\title{
Epidemiology and economic loss of fasciolosis and dicrocoeliosis in Arak, Iran
}

\author{
Mohsen Arbabi, Elnaz Nezami, Hossein Hooshyar and Mahdi Delavari \\ Department of Medical Parasitology and Mycology, School of Medicine, Kashan University of Medical Sciences, Kashan, \\ Iran. \\ Corresponding author: Mohsen Arbabi, e-mail: arbabi4.mohsen@yahoo.com \\ Co-authors: EN: elnaznezami1370@yahoo.com, HH: hooshyar4@yahoo.com, MD: mdelavari1@gmail.com \\ Received: 04-08-2018, Accepted: 23-10-2018, Published online: 10-12-2018
}

doi: 10.14202/vetworld.2018.1648-1655 How to cite this article: Arbabi M, Nezami E, Hooshyar H, Delavari M (2018) Epidemiology and economic loss of fasciolosis and dicrocoeliosis in Arak, Iran, Veterinary World, 11(12): 1648-1655.

\begin{abstract}
Aim: Fasciolosis and dicrocoeliosis are important parasitic diseases worldwide, causing significant financial losses due to decrease in production and viscera condemnation in animals. We performed the current research to assess the epidemiology of these infections and determine their significance from an economic perspective in Arak, Iran.

Materials and Methods: In total, we evaluated 118,463 sheep, 207,652 goats, and 43,675 cattle through necropsic analysis at the slaughterhouses. The average weight of sheep, goat, and cattle liver was 1000,900 , and 5000 g, respectively. The average price of liver in the market was $8 \mathrm{USD} / \mathrm{kg}$. Moreover, the elimination of fundamental nutrients and vitamins was evaluated in infected livers. The prevalence of fasciolosis and dicrocoeliosis was determined. Analysis of variance test was applied for the statistical analysis, and the significance level was $<0.05$.
\end{abstract}

Results: In total, Fasciola hepatica and Dicrocoelium dendriticum were detected in 0.56\% (confidence interval CI, $0.54-0.59)$ and $0.77 \%$ (CI, 0.75-0.81) of the animals, respectively ( $\mathrm{p}=0.1)$. The annual economic loss attributed to fasciolosis and dicrocoeliosis was 26698.4 and 30479.2 USD, respectively. The total economic loss was 10,880, 9079.2, and 10,520 dollars in sheep, cattle, and goats, respectively. On the other hand, financial loss resulting from fasciolosis was 7160, 6098.4, and 13,440 dollars in sheep, goats, and cattle, respectively. In addition, economic loss due to dicroceliasis was 10,880, 9079.2, and 10,520 dollars, respectively.

Conclusion: Overall, fasciolosis and dicrocoeliosis in Iran always remain common in sheep, goats, and cattle that afford major economic loss of all the country also exist in Arak province. The present study could provide basic information for further examination of liver fluke infections in Iran.

Keywords: dicrocoeliosis, economic loss, epidemiology, fasciolosis, Iran, slaughtered animal.

\section{Introduction}

Farm animals play a significant role in human nutrition and socioeconomic evolution and development. Animal products such as milk and meat are a significant source of micronutrients, energy, and protein supply provided approximately $15 \%$ of energy and $30 \%$ of protein worldwide. In developing countries, with the increase in the number of residents and income growth, the use of animal protein per capita, with the global consumption of meat, is projected to increase by nearly $73 \%$ by 2050 [1]. Planning to these ensuring needs, as a major mission, leads to increased productivity of the production system, pasture management, food chains, and markets, and ultimately, and animal health [2]. Infectious diseases have been a serious threat to animal health and productivity in developing countries. A significant proportion of diseases affect the safety of food supplies, in addition to

Copyright: Arbabi, et al. Open Access. This article is distributed under the terms of the Creative Commons Attribution 4.0 International License (http://creativecommons.org/licenses/by/4.0/), which permits unrestricted use, distribution, and reproduction in any medium, provided you give appropriate credit to the original author(s) and the source, provide a link to the Creative Commons license, and indicate if changes were made. The Creative Commons Public Domain Dedication waiver (http://creativecommons.org/ publicdomain/zero/1.0/) applies to the data made available in this article, unless otherwise stated. or instead of, their effect on the volume and quality of food products. Parasitological diseases, including those caused by trematodes, have widely differing effects on meat, milk, and fiber production and many new technologies have been developed to prevent or treat them $[3,4]$. Trematode infections such as dicrocoeliosis and fasciolosis in farm animals are an important parasitic disease cause serious economic losses to livestock worldwide. Fasciola species and Dicrocoelium dendriticum are recognized as the most common liver flukes through many regions of Asia including Iran [5-7]. These helminths are foodborne trematode zoonosis in ruminant and should be regarded as serious animal health problems in many urban and rural of the area, due to the rising number of infections in humans [8-10]. Goats, cattle, and sheep are the major definitive hosts of liver flukes. Nevertheless, in some cases, humans might act as incidental hosts and fasciolosis is recognized as emerging disease [11]. Fasciolosis due to Fasciola hepatica has a broad geographical distribution as a plant-borne zoonotic disease and occurs in $>51$ countries, especially where sheep and cattle are reared $[12,13]$. Trematode infections cause serious animal's health problem and economic losses to livestock in many rural and urban areas of the world. The global economic burden of 
fasciolosis causing significant financial losses alone due to mortality, morbidity, decrease in production and growth rate, condemnations of the liver, and increased susceptibility to secondary infections and the expense of control measures in animal farming is considerable and is exceeding to 3 billion dollars each year for agricultural populations and producers $[4,10,14-17]$.

Moreover, the infection has been reported in over 300 million cattle, as well as 250 million sheep around the world [18]. In fact, such losses can impose both direct and indirect losses. Host mortality and liver condemnation for the direct burdens of fasciolosis and dicrocoeliosis are significant.

On the other hand, indirect losses include reduced product quality, decreased rate of production, slow development, fertility impairment, and increased costs of stock replacement, and anthelmintic treatments [19-21]. In industrial countries, the prevalence of $F$. hepatica infection can reach up to $77 \%$, and losses due to fasciolosis in some areas are $>70.67$ million pounds a year $[9,22]$. There is insufficient literature on the economic impact of dicrocoeliosis and fasciolosis in Iran. Therefore, it is necessary to perform research on the financial burdens of fasciolosis and dicrocoeliosis in this region. Fasciolosis, with a prevalence of $30-90 \%$, is the most prevalent infection among cattle in tropical regions [18]. Considering its economic significance, fasciolosis has recently reemerged as a prevalent zoonotic disease, affecting different populations. At present, the infection has been reported as an important zoonosis for public health with up to 2.4-17 million people around the world; moreover, 180 million individuals are exposed to the risk $[18,23]$. Access to healthy sources of protein is necessary due to population growth. In different communities, the livestock provides the necessary proteins for people. Despite great progress in health-care provision and disease prevention, economic loss, resulting from food-borne liver fluke diseases, is still a major problem. According to statistics, the amount of financial loss is considerably every year. In general, financial losses arise from treatment costs, preventive measures for disease transmission, increased livestock mortality, and disposal of livestock [10]. Prevalence of fasciolosis in 13 Asian countries indicates with the highest range in cattle (0.71-69.2\%) and lowest in goat (0.0-47.0\%) [10]. Among Asian countries, Iran is one of the most important foci of the disease, and annually highest reports are recorded from the various provinces of this country [24]. In fact, both F. hepatica and Fasciola gigantica species are endemic to northern and western regions of Iran [24-26]. Reports show that the prevalence has been reported in sheep (0.35-31.25\%), goat $(0.20-4.4 \%)$, and cattle $(0.71-81.5 \%)$, there are significant seasonal differences in the prevalence of Fasciola spp. [7,27-29].

The financial losses due to the condemnation of livers in Asian countries were calculated to be until
17.02 million USD annually [10]. Dicrocoeliosis is a hepatic parasitic infection affecting grazing ruminants and humans; however, it is found to be less severe than fasciolosis. The financial burden due to this infection is mainly attributed to liver condemnation [30]. A nationwide review of Dicrocoelium infection in slaughterhouses showed a prevalence of at least $0.1 \%$ up to $29.32 \%$ in Iran. The highest prevalence belongs to East Azerbaijan Province in northwestern, and the lowest belongs to Fars Province in the south of Iran $[28,31,32]$.

Overall, scant research has focused on the economic loss and its public health significance of fasciolosis and dicrocoeliosis at national and regional levels; in fact, there is no adequate information on this region. So, we aimed to, determine the prevalence of fasciolosis and dicrocoeliosis in ruminant and, evaluated economic loss caused by the condemnation of livers at abattoirs of Arak in the center of Iran.

\section{Materials and Methods}

\section{Ethical approval}

The project was found to be in accordance with the ethical principles and standards for conducting medical research. This project was approved by Research Ethics Committee, Faculty of Medicine of Kashan University of Medical Sciences, Iran.

\section{Study area}

Arak is a city of Markazi Province, Iran (Figure-1). It is located 34.09 latitude and 49.69 longitudes, and it is situated at elevation of 1750 meters above sea level. Arak has a Mediterranean continental climate that is, in general, relatively cold and dry. The average rainfall is around $350 \mathrm{~mm}$, and the annual relative humidity is $46 \%$. Arak has a population of 503,647 making it the biggest city in Markazi province.

\section{Study design}

In this cross-sectional study, data were collected during 2013-2016 to evaluate the prevalence of infection in the abattoirs of Arak and determine direct

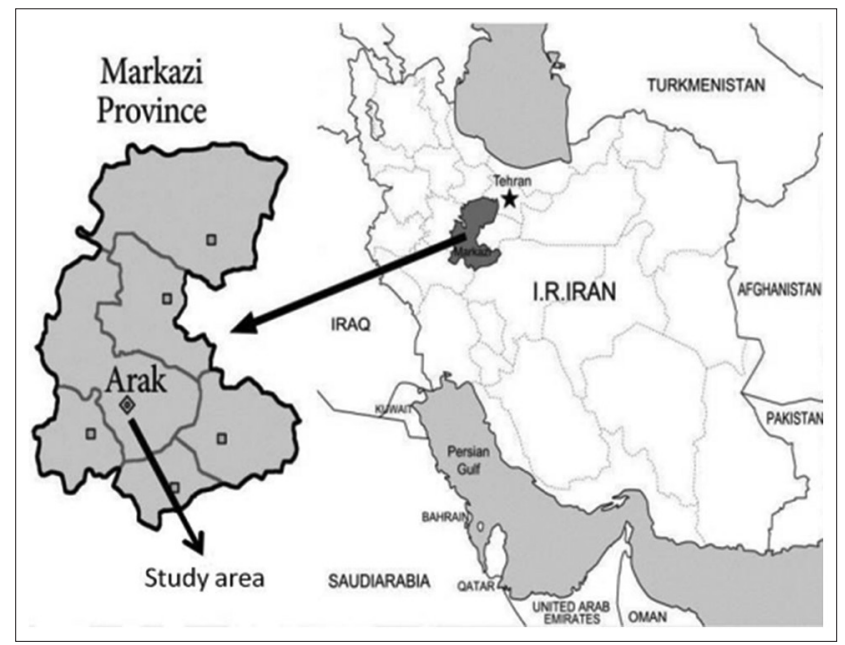

Figure-1: Map of study area. 
economic losses, resulting from liver condemnation through postmortem analysis. Through visualization and palpation, the liver and bile duct were examined.

\section{Study animals}

Overall, 369,790 slaughtered sheep, goats, and cattle were recorded during necropsic analysis. Fasciola and Dicrocoelium parasites were evaluated in the removed liver and gallbladder. The species of parasites were identified, using the morphological characterization of $F$. hepatica, F. gigantica, and D. dendriticum.

\section{Estimation of economic loss}

To determine the annual financial loss, the average number of slaughtered animals (per year in the abattoirs) was multiplied by the prevalence of infection in the current study and the mean price of liver in the region. We summarized the results for each year to determine the number of infected livers in animals. Using the available information, economic loss was estimated during 2013-2016. The total quantities were converted to US dollar. Moreover, direct economic loss imposed by fasciolosis and dicrocoeliosis was measured as follows:

\section{$\mathrm{DFL}=\mathrm{N} \times \mathrm{P} \times \mathrm{W}$}

In this equation, DFL denotes direct financial loss, $\mathrm{N}$ represents the number of condemned livers, $\mathrm{P}$ is the average price of liver $(\$ / \mathrm{kg})$, and $\mathrm{W}$ denotes the average weight of liver $(\mathrm{kg})$. The average weight of the liver was measured by weighing 118,463 sheep, 207,652 goats, and 43,675 cattle livers. Furthermore, the average weight was measured to be 1000,900 , and $5000 \mathrm{~g}$ in sheep, goats, and cattle, respectively. According to interviews with local butchers, the average price of liver was 250,000 Rials/kg ( 8 dollars).

\section{Estimation of nutritional value}

Minerals and vitamins were measured in each $100 \mathrm{~g}$ of liver, according to the protocol proposed by the United States Department of Agriculture [33].

\section{Statistical analysis}

The data was processed by Microsoft Excel 2017 and IBM SPSS Statistics (Ver. 16, US) for determination of significant difference between variables. To evaluate the prevalence of fasciolosis and dicrocoeliosis, the number of animals infected with Fasciola and Dicrocoelium species was calculated $(95 \%$ confidence interval). The number of infected cases was divided by the total number of slaughtered animals and multiplied by 100. Furthermore, for the comparison of fasciolosis and dicrocoeliosis in terms of prevalence, Analysis of variance test was carried out used to compare the prevalence of fasciolosis and dicrocoeliosis in different animals. Chi-squared test was used to analyze the effect of the season on the prevalence of the disease. The significance level was considered when the probability value $\mathrm{p}<0.05$.

\section{Results}

Overall, 369,790 slaughtered animals $(118,463$ sheep, 207,652 goats, and 43,675 cattle) were slaughtered and evaluated for Fasciola and Dicrocoelium species at Arak abattoirs, of which $2105(0.56 \%)$ and $2884(0.77 \%)$ were infected, respectively. The prevalence of Fasciola infection was $0.75 \%, 0.42 \%$, and $0.76 \%$ in sheep, goats, and cattle, while the prevalence of Dicrocoelium infection was $1.14 \%, 0.60 \%$, and $0.60 \%$, respectively. However, the difference in prevalence rates of fasciolosis $(\mathrm{p}=0.21)$ and dicrocoeliosis $(p=0.16)$ was not significant in various hosts (Table-1).

Furthermore, the prevalence of fasciolosis and dicrocoeliosis was evaluated during 4 seasons, as shown in Table-2. The prevalence of Fasciola infection in all hosts was the highest during winter, and the difference was significant $(\mathrm{p}=0.04)$. However, no seasonal trend was found in the prevalence of dicrocoeliosis, and differences were not of significance ( $p>0.1)$.

The evaluation of economic impacts due to the Fasciola infection in the area study shows alarming values: $895 \mathrm{~kg}$ of sheep livers, $762 \mathrm{~kg}$ of goat livers, and $1680 \mathrm{~kg}$ of cattle livers were condemned. In addition, $1360 \mathrm{~kg}$ of sheep livers, $1135 \mathrm{~kg}$ of goat livers, and $1315 \mathrm{~kg}$ of cattle livers infected with dicrocoeliosis. Based on the analysis of market prices in Arak, the average price of $1 \mathrm{~kg}$ of liver was reported to be 8 dollars. The average annual loss of meat and offals, resulting from Fasciola and Dicrocoelium infections, was estimated at 26698.4 and 30479.2 USD, respectively. Overall, 7160, 6098.4, and 13,440 USD were lost due to fasciolosis in sheep, goats, and cattle, respectively. In addition, economic loss due to Dicrocoelium infection was 10,880, 9079.2, and 10,520 USD in sheep, goats, and cattle, respectively (Table-3).

Tables- 4 and 5 present the analysis of macronutrient, vitamin, and mineral elimination in the liver of animals infected with Fasciola and Dicrocoelium species.

\section{Discussion}

Growing populations and urbanization are translating into increased demand for livestock products, particularly in developing countries. Livestock has an essential role in socioeconomic and nutrition development. Global food security will require the production of more food using resources, including and more efficiently, and with less waste. Infectious disease is the main constraint of biologically efficient livestock production and both endemic and exotic disease results in mortality and morbidity and hence less food than should ideally be available in current farming systems $[1,3,10]$. Trematode infections occur worldwide, and widely differing effects on milk, meat, and fiber production and many new technologies have been developed to prevent or treat them. Approaches to developing better control of 
Available at www.veterinaryworld.org/Vol.11/December-2018/1.pdf

Table-1: The prevalence of condemned livers resulting from Fasciola hepatica, Fasciola gigantica, and Dicrocoelium dendriticum at slaughterhouses of Arak, Iran.

\begin{tabular}{|c|c|c|c|c|c|c|c|}
\hline \multirow[t]{2}{*}{ Host } & \multirow[t]{2}{*}{ Examined number } & \multicolumn{2}{|c|}{ Fasciolosis } & \multirow[t]{2}{*}{$95 \% \mathrm{CI}$} & \multicolumn{2}{|c|}{ Dicrocoeliosis } & \multirow[t]{2}{*}{$95 \%$ CI } \\
\hline & & $\begin{array}{c}\text { Infected liver } \\
\text { number }\end{array}$ & Prevalence $\%$ & & $\begin{array}{c}\text { Infected liver } \\
\text { number }\end{array}$ & Prevalence \% & \\
\hline Sheep & 118,463 & 895 & 0.75 & $0.7-0.8$ & 1360 & 1.14 & $1.08-1.2$ \\
\hline Goat & 207,652 & 874 & 0.42 & $0.39-0.44$ & 1261 & 0.6 & $0.56-0.64$ \\
\hline Cattle & 43,675 & 336 & 0.76 & $0.68-0.84$ & 263 & 0.6 & $0.52-0.67$ \\
\hline Total & 369,790 & 2105 & 0.56 & $0.54-0.59$ & 2884 & 0.77 & $0.75-0.81$ \\
\hline \multicolumn{2}{|c|}{ Difference between hosts } & \multicolumn{2}{|c|}{$p=0.21$} & - & \multicolumn{2}{|c|}{$p=0.16$} & - \\
\hline
\end{tabular}

$\mathrm{CI}=$ Confidence interval

Table-2: Seasonal prevalence of liver condemnation resulting from Fasciola hepatica, Fasciola gigantica, and Dicrocoelium dendriticum in sheep, goats, and cattle at abattoirs of Arak, Iran.

\begin{tabular}{|c|c|c|c|c|c|c|c|c|c|}
\hline \multirow[t]{2}{*}{ Season } & \multicolumn{3}{|c|}{ Slaughtered number } & \multicolumn{2}{|c|}{ Sheep infected number $\%$} & \multicolumn{2}{|c|}{ Goat infected number \% } & \multicolumn{2}{|c|}{ Cattle infected number \% } \\
\hline & Sheep & Goat & Cattle & Fasciolosis & Dicrocoeliosis & Fasciolosis & Dicrocoeliosis & Fasciolosis & Dicrocoeliosis \\
\hline & & & & & & & & & \\
\hline & & & & & & & & & \\
\hline & & & & & & & & & \\
\hline & & 17110 & 10328 & & & & & $129(1.24)$ & $68(0.65)$ \\
\hline Total & 118,463 & 207652 & 43675 & $895(0.75)$ & $1360(1.14)$ & $874(0.42)$ & $1261(0.60)$ & $336(0.76)$ & $263(0.60)$ \\
\hline
\end{tabular}

Table-3: The annual financial loss resulting from Fasciola hepatica, Fasciola gigantica, and Dicrocoelium dendriticum in slaughtered animals.

\begin{tabular}{|c|c|c|c|c|c|}
\hline \multirow[t]{2}{*}{ Host } & \multirow{2}{*}{$\begin{array}{c}\text { Examined } \\
\text { number }\end{array}$} & \multirow{2}{*}{$\begin{array}{c}\text { Fasciolosis } \\
\begin{array}{c}\text { Infected liver } \\
\text { number }\end{array}\end{array}$} & \multirow{2}{*}{$\begin{array}{c}\text { Economic } \\
\text { losses (USD) }\end{array}$} & \multirow{2}{*}{$\begin{array}{c}\text { Dicrocoeliosis } \\
\begin{array}{c}\text { Infected liver } \\
\text { number }\end{array}\end{array}$} & \multirow{2}{*}{$\begin{array}{c}\text { Economic } \\
\text { losses (USD) }\end{array}$} \\
\hline & & & & & \\
\hline Sheep & 118,463 & 895 & 7160 & 1360 & 10880 \\
\hline Goat & 207,652 & 874 & 6098.4 & 1261 & 9079.2 \\
\hline Cattle & 43,675 & 336 & 13440 & 263 & 10520 \\
\hline Total & 369,790 & 2105 & 26698.4 & 2884 & 30479.2 \\
\hline
\end{tabular}

Table-4: The macronutrients and mineral waste in livers infected with Fasciola hepatica, Fasciola gigantica, and Dicrocoelium dendriticum in abattoirs.

\begin{tabular}{lccccccc}
\hline Macronutrients & \multicolumn{3}{c}{ Fasciolosis } & & \multicolumn{3}{c}{ Dicrocoeliosis } \\
\cline { 2 - 3 } & Sheep & Goat & Cattle & & Sheep & Goat & Cattle \\
\hline Water (g) & 158,616 & 199405 & 297402 & & 241026 & 201133 & 232788 \\
Energy (kcal) & 313,250 & 275310 & 567000 & & 476000 & 397215 & 443813 \\
Protein (g) & 593.375 & 39192.3 & 85512 & & 67762 & 56546.4 & 66933.5 \\
Total lipid (fat) (g) & 10851.9 & 9537.53 & 14112 & & 16490 & 13760.7 & 11046 \\
Carbohydrate, & $6,511,125$ & 5722.52 & 16338 & & 9894 & 8256.4 & 12788.4 \\
difference (g) & 1118.75 & 9832.5 & 21000 & & 17000 & 14186.3 & 16437.5 \\
Calcium (mg) & 14,320 & 12585.6 & 20580 & & 21760 & 18158.4 & 16108.8 \\
Iron (m) & 4475 & 39330 & 75600 & & 6800 & 56745 & 13150 \\
Magnesium (mg) & 848,013 & 745304 & 1625400 & & 1288600 & 1075318 & 59175 \\
Phosphorus (mg) & 689,150 & 605682 & 1314600 & & 1047200 & 783873 & 1272263 \\
Potassium (mg) & 172,288 & 151421 & 289800 & & 261800 & 218468 & 1028988 \\
Sodium (mg) & 26894.8 & 23637.3 & 16800 & & 40868 & 34103.7 & 226838 \\
Zinc (mg) & & & & & & \\
\hline
\end{tabular}

infection have included livestock breeding strategies, improved nutrition and management, and the development of new drugs, and diagnostic tests and vaccines [3].

Recently, human fasciolosis and dicrocoeliosis occurred occasionally but are now increasingly reported from entire the world. No continent is free from these diseases, and it is likely that where animal cases are reported, human cases also exist. The number of human cases affected by Fasciola spp. has increased drastically. Fasciolosis has many complications in humans. During the acute phase (caused by the migration of the immature fluke through the hepatic parenchyma), manifestations include fever, vomiting, diarrhea, abdominal pain, hepatomegaly, urticaria and eosinophilia, and can last for months. 
Table-5: The level of Group B vitamin elimination in livers infected with Fasciola hepatica, Fasciola gigantica, and Dicrocoelium dendriticum at Arak abattoirs.

\begin{tabular}{|c|c|c|c|c|c|c|}
\hline \multirow[t]{2}{*}{ Vitamins } & \multicolumn{3}{|c|}{ Fasciolosis } & \multicolumn{3}{|c|}{ Dicrocoeliosis } \\
\hline & Sheep & Goat & Cattle & Sheep & Goat & Cattle \\
\hline Vitamin C (mg) & 1566.25 & 1376.55 & 5460 & 2380 & 1986.075 & 4273.75 \\
\hline Thiamin (mg) & 387.0875 & 338.675 & 793.8 & 588.2 & 488.6375 & 621.3375 \\
\hline Riboflavin (mg) & 5459.5 & 4798.26 & 11571 & 8296 & 6922.89 & 9057.06225 \\
\hline Niacin (mg) & 23605.625 & 20746.575 & 55325 & 35870 & 29932.9875 & 43312.8125 \\
\hline Vitamin B6 (mg) & 2181.5625 & 1881.285 & 4548.6 & 3315 & 2714.3025 & 3560.3625 \\
\hline Folate, DFE $(\mu \mathrm{g})$ & 279687.5 & 245812.5 & 8000 & 425000 & 354656.25 & 9533750 \\
\hline Vitamin B-12 $(\mu \mathrm{g})$ & 133914.375 & 117695.025 & 249060 & 203490 & 169809.41 & 194948.75 \\
\hline Vitamin A, RAE Vitamin B-12 $(\mu \mathrm{g})$ & 523.21 & 23021815.5 & 20865600 & 39803800 & 33215685.75 & 16332300 \\
\hline Vitamin A, IU & $87,387,800$ & 76803624 & 70971600 & 132790400 & 110811636 & 55552175 \\
\hline Vitamin E (mg) & 827.875 & 727.605 & 1596 & 1258 & 1049.7825 & 1249.25 \\
\hline Vitamin K ( $\mu \mathrm{g})$ & 2013.75 & 2553.525 & 13020 & 3060 & 2837.25 & 10191.25 \\
\hline
\end{tabular}

In the chronic phase (caused by the adult fluke within the bile ducts), the symptoms are more discrete and reflect intermittent biliary obstruction and inflammation. Occasionally, ectopic locations of infection (such as intestinal wall, lungs, subcutaneous tissue, and pharyngeal mucosa) can occur [34]. Different pathology studies in recent years proved that human infection is not only a serious health problem during the acute phase but also during the very long chronic period [35]. Most infections due to $D$. dendriticum infection in humans are light and asymptomatic. In heavier infections, symptoms may include abdominal pain, biliary colic, digestive disturbances, liver abscesses hepatomegaly, cirrhosis, cholecystitis, and seldom skin rash urticaria [36].

Based on the findings, fasciolosis and dicrocoeliosis are serious problems in the slaughterhouses of Arak, Iran, and impose great financial losses due to liver condemnation and weight loss. The prevalence of Fasciola and Dicrocoelium infections was $0.56 \%$ and $0.77 \%$, respectively, which was relatively insignificant. Moreover, the prevalence of fasciolosis was $0.75 \%$ in sheep, $0.42 \%$ in goats, and $0.76 \%$ in cattle. Furthermore, the prevalence of dicrocoeliosis was $0.60 \%$ in goats, $1.14 \%$ in sheep, and $0.60 \%$ in cattle. The prevalence of liver fluke infections in ruminants depends on some factors such as the environment, the climate, and the choice of diagnostic methods. Changes in climatic conditions are closely correlated with changes in the prevalence of animal fasciolosis [37].

Obviously, husbandry conditions of the sheep (i.e., more contact with intermediate parasite hosts in comparison with cattle and goats) majorly contribute to the high incidence of diseases in sheep. Nevertheless, cattle and goats might show hereditary resistance. In the current research, fasciolosis $(0.56 \%)$ was less prevalent in comparison with similar results which have been reported by Khoramian et al. [38] with 3.28\%, Khosravi and Babbahamdy [39] with $8.48 \%$, and Abdi et al. [40] with $0.98 \%$ in different parts of Iran. Our result is lower than these values.
Moreover, in the current research, the prevalence was lower than that found in Zimbabwe with $37 \%$ [41], in Kenya with 26\% [42], in Zambia with 46\% [43], in Southwest Zambia with 53.7\% and $53.9 \%$ [44,45], and in Egypt with 14.7\% [46].

In some regions of Iran, the prevalence of fasciolosis is low. Similar results have been reported in slaughterhouses in some regions of Iran. In this regard, Khoramian et al. [38] have reported similar findings in the present study. In their study, the prevalence of Fasciola infections was estimated at 3.28\%, $2.76 \%$, and $3.68 \%$ in sheep, goats, and cattle, respectively Khanjari et al. [7] reported slightly different results and showed an average prevalence of $6.6 \%$ for Fasciola infections in sheep and goats in the abattoirs of Amol in the north of Iran. Moreover, Khosravi and Babbahamdy [39] described a prevalence of $8.48 \%$ in the abattoirs of Ilam, Iran. The discrepancies in the prevalence of these infections might be attributed to significant differences between these studies in climatic conditions, including the average rainfall, temperature, seasonal changes, type of animals, and livestock management strategies [47]. Comparison of the present study with previous research indicated the reduced prevalence of liver fluke diseases in Iran, which might be associated with droughts, hindering disease transmission. Measures such as effective management of slaughtered animals have resulted in reduced prevalence of Fasciola and Dicrocoelium diseases; therefore, today, healthier animals enter the market. Two great features differentiate the epidemiology of $D$. dendriticum from Fasciola species. First, moist environment is not necessary for the intermediate hosts of Dicrocoelium species, which are widely present in meadows. Second, fluke eggs are able to survive on pastures for a long time [48]. The highest prevalence of Fasciola infections among all evaluated animals was reported during winter. This finding may be associated with meteorological evidence, which predicts many rainfalls during autumn and winter; furthermore, infection is quite prevalent in snails during rainy seasons. In general, it takes 12-16 weeks for a parasite to mature after infection; 
therefore, patent infection is predicted to be prevalent during winter [8].

The reduced rate of production, decreased growth rate of animals, and production of low-quality livestock products for humans, increased susceptibility to secondary infections, and cost of disease control measures are among the consequences of fluke infestation $[49,50]$.

Furthermore, severe infestation might directly or indirectly lead to mortality through triggering or intensifying diseases. Today, scarce data are available regarding the presence of minerals and vitamins in the livers of infected animals; furthermore, the literature on this subject has not been reviewed so far.

The connection between economic loss and diseases, such as fasciolosis and dicrocoeliosis, is of great significance, especially regarding the nutritional elements removed from the humans' nutrient cycle due to parasitic diseases. No records are available on the financial burden of fascioliasis and dicrocoeliosis in this region of Iran. Based on the findings, the prevalence and economic significance of fasciolosis and dicrocoeliosis were considerable in livestock slaughtered at Arak abattoirs.

However, in the present study, the annual economic loss was still moderately high. The high prevalence of infection is indicative of appropriate conditions for the growth and survival of parasites. The present findings highlight the importance of these diseases in farm animals and indicate the need for the development of control measures by studying the economic burdens and evaluating the local epidemiology of diseases. In the present study, the total annual economic loss was higher than that reported in Asella, Ethiopia [51]. Differences in the number of slaughtered animals in abattoirs and the average market price of liver and meat in different regions might account for the differences in economic loss in the studied regions.

The current findings showed that fasciolosis and dicrocoeliosis are still major risk factors for the health of livestock products in Arak, Iran. The financial loss resulting from liver condemnation and indirect weight loss was substantial in this study; therefore, adoption of control and prevention strategies is necessary.

\section{Conclusion}

Fasciolosis and dicrocoeliosis were common and economically important infections in cattle, sheep, and goats at Arak slaughterhouses. Furthermore, the annual direct economic loss due to the condemnation of livers infested is relatively high. By studying the economic significance of these diseases and evaluating the local epidemiology, more practical and effective control strategies can be developed to prevent and limit the infection and reduce economic significant.

\section{Authors' Contributions}

MA designed, overseeing the research project, interpretation of data, and manuscript writing; EN collected the data, $\mathrm{HH}$ and $\mathrm{MD}$ helped in writing and review of the manuscript. All authors read and approved the final manuscript.

\section{Acknowledgments}

We extend our gratitude to the inspectors, traders, butchers, and field staff for their assistance and collaboration. This study was extracted from a project, approved by Kashan University of Medical Sciences, Iran (No., 94148).

\section{Competing Interests}

The authors declare that they have no competing interests.

\section{References}

1. FAO. (2011) World Livestock, Livestock in Food Security. Food and Agriculture Organization, Rome.

2. Cardona, G.A. and Carmena, D. (2013) A review of the global prevalence, molecular epidemiology and economics of cystic echinococcosis in production animals. Vet. Parasitol., 192(1-3): 10-32.

3. Fitzpatrick, J.L. (2013) Global food security: The impact of veterinary parasites and parasitologists. Vet. Parasitol., 195(3-4): 233-248.

4. Elliott, T.P., Kelley, J.M., Rawlin, G. and Spithill, T.W. (2015) High prevalence of fasciolosis and evaluation of drug efficacy against Fasciola hepatica in dairy cattle in the Maffra and Bairnsdale districts of Gippsland, Victoria, Australia. Vet. Parasitol., 209(1-2): 117-124.

5. Kantzoura, V., Kouam, M.K., Feidas, H., Teofanova, D. and Theodoropoulos, G. (2011) Geographic distribution modeling for ruminant liver flukes (Fasciola hepatica) in SouthEastern Europe. Int. J. Parasitol., 41(7): 747-753.

6. Massoud, A.M., Shalaby, H.A., El Khateeb, R.M., Mahmoud, M.S. and Kutkat, M.A. (2012) Effects of mirazid and myrrh volatile oil on adult Fasciola gigantica under laboratory conditions. Asian Pac. J. Trop. Biomed., 2(11): 875-884.

7. Khanjari, A., Bahonar, A.R., Fallah, S., Bagheri, M., Alizadeh, A., Fallah, M. and Khanjari, Z. (2014) Prevalence of fasciolosis and dicrocoeliosis in slaughtered sheep and goats in Amol abattoir, Mazandaran, Northern Iran. Asian Pac. J. Trop. Dis., 4(2): 120-124.

8. Mas-Coma, S., Valero, M.A. and Bargues, M.D. (2009) Chapter 2. Fasciola lymnaeids and human fascioliasis, with a global overview on disease transmission, epidemiology, evolutionary genetics, molecular epidemiology and control. Adv. Parasitol., 69: 41-146.

9. Bekele, M., Tesfay, H. and Getachew Y. (2010) Bovine fasciolosis: Prevalence and its economic loss due to liver condemnation at Adwa Municipal Abattoir, North Ethiopia. EJAST, 1(1): 39-47.

10. Mehmood, K., Zhang, H., Sabir, A.J., Abbas, R.Z., Ijaz, M., Durrani, A.Z., Saleem, M.H., Ur Rehman, M, Iqbal, M.K., Wang, Y., Ahmad, H.I., Abbas, T., Hussain, R., Ghori, M.T., Ali, S., Khan, A.U. and Li, J. (2017) A review on epidemiology, global prevalence and economic losses of fasciolosis in ruminants. Microb. Pathog., 109: 253-262.

11. McCann, C.M., Baylis, M. and Williams, D.J. (2010) The development of linear regression models using environmental variables to explain the spatial distribution of Fasciola hepatica infection in dairy herds in England and Wales. Int. J. Parasitol., 40(9): 1021-1028.

12. Mas-Coma, S. (2005) Epidemiology of fascioliasis in 
human endemic areas. J. Helminthol., 79(5): 207-216.

13. Freitas, D.V.F., Martins, I., Mada dos Santos, G., R dos Santos, A. and da Silva Gomes D. (2014) Bioclimatic distribution and prevalence maps for Fasciola hepatica in Espírito Santo State, Brazil. J. Venom. Anim. Toxins Inc. Trop. Dis., 20(5): 1-11.

14. Elelu, E. and Eisler, M.C. (2018) A review of bovine fasciolosis and other trematode infections in Nigeria. J Helminthol., 92(2): 128-141.

15. Henok, M. and Mekonnen, A. (2011) Study on the ruminants in and around Hirna town, Ethiopia. Glob. Vet., 7(5): 497-501.

16. Ayaz, S., Ullah, R., AbdEl-Salam, N.M., Shams, S. and Niaz, S. (2014) Fasciola hepatica in some buffaloes and cattle by PCR and microscopy. Sci. World J., 2014(2014): 462084.

17. Olsen, A., Frankena, K., Rene' Bødker, N.T., Thamsborg, S.M., Enemark, H.L. and Halasa T. (2015) Prevalence, risk factors and spatial analysis of liver fluke infections in Danish cattle herds. Parasit. Vectors, 15(2): 160-168.

18. Aliyu, A.A., Ajogi, I.A., Ajanusi, O.J. and Reuben, R.C. (2014) Epidemiological studies of Fasciola gigantica in cattle in Zaria, Nigeria using coprology and serology. J. Public Health Epidemiol., 6(2): 85-91.

19. Bennema, S., Ducheyne, E., Vercruysse, J., Claerebout, E., Hendrickx, G. and Charlier, J. (2011) Relative importance of management, meteorological and environmental factors in the spatial distribution of Fasciola hepatica in dairy cattle in a temperate climate zone. Int. J. Parasitol., 41(2): 225-233.

20. Chakiso, B., Menkir, S. and Desta, M. (2014) On farm study of bovine fasciolosis in Lemo district and its economic loss due to liver condemnation at Hossana Municipal abattoir, Southern Ethiopia. Int. J. Curr. Microbiol. Appl. Sci., 3(4): $1122-1132$.

21. Brockwell, Y.M., Elliott, T.P, Anderson, G.R, Stanton, R., Spithill, T.W. and Sangster, N.C. (2014) Confirmation of Fasciola hepatica resistant to triclabendazole in naturally infected Australian beef and dairy cattle. Int. J. Parasitol. Drugs Drug Resist., 4(1): 48-54.

22. Morgan, E.R., Charlier, J., Hendrickx, G., Biggeri, A., Catalan, D., von Samson-Himmelstjerna, G. and Vercruysse, J. (2013) Global change and helminth infections in grazing ruminants in Europe: Impacts, trends and sustainable solutions. Agriculture, 3(3): 484-502.

23. Dida, G.O., Gelder, F.B., Anyona, D.N., Matano, A.S., Abuom, P.O., Adoka, S.O. and Ofulla, A.V. (2014) Distribution and abundance of schistosomiasis and fascioliasis host snails along the Mara River in Kenya and Tanzania. Infect. Ecol. Epidemiol., 4(1): 24281.

24. Amor, N., Halajian, A., Farjallah, S., Merella, P., Said, K. and Ben Slimane, B. (2011) Molecular characterization of Fasciola spp. From the endemic area of Northern Iran based on nuclear ribosomal DNA sequences. Exp. Parasitol., 128(3): 196-204.

25. Moghaddam, A.S., Massoud, J., Mahmoodi, M., Mahvi, A.H., Periago, M.V., Artigas, P., Fuentes, M.V., Bargues, M.D., Mas-Coma, S. (2004) Human and animal fascioliasis in Mazandaran province, Northern Iran. Parasitol. Res., 94(1): 61-69.

26. Bozorgomid, A., Nazari, N., Kia, E.B., Mohebali, M., Hajaran, H., Heydarian, P., Hamzavi, Y., Nemati, S., Aryaeipour, M. and Rokni, M.B. (2018) Epidemiology of fascioliasis in Kermanshah Province, Western Iran. Iran. J. Public Health, 47(7): 967-972.

27. Ashrafi, K. (2015) The status of human and animal fascioliasis in Iran: A narrative review article. Iran J. Parasitol. 10(3): 306-328.

28. Ezatpour, B., Hasanvand, A., Azami, M., Mahmoudvand, H. and Anbari, K.H. (2014) A slaughterhouse study on prevalence of some helminths of cattle in Lorestan Province,
West Iran. Asian Pac. J. Trop. Dis., 4(5): 416-420.

29. Arjmand, H.J., Mahdi N.S., Khojasteh, B., Baran A.I., Mirshekar, F., Ghashghaei, O., Samiei, K. and Faramarzpour, A. (2015) Prevalence, macroscopic and microscopic lesions of bovine fasciolosis at Ahvaz abattoir, Khuzestan Province, Iran. Biol. Forum, 7(1): 539-545.

30. Rokni, M.B. (2008) The present status of human helminthic diseases in Iran. Ann. Trop. Med. Parasitol., 102(5): 283-295.

31. Arbabi, M., Dalima, A., Ghafarifar, F. and Foorozaneh, M.M. (2011) Prevalence and Intensity of Dicrocoelium dendriticum in sheep and goats of Iran. Res. J. Parasitol., 6(5): 160-167.

32. Jahed, K.G., Beigom, K.E. and Raei, M. (2013) Liver condemnation and economic losses due to parasitic infections in slaughtered animals in Iran. J. Parasit. Dis., 37(2): 240-244.

33. United States Department of Agriculture. National Nutrient Database for Standard Reference. Beltsville: United States Department of Agriculture. (2011) Available from: http:// www.ndb.nal.usda.gov/ndb/search/list. Last accessed on 08-02-2014.

34. Valero, M.A., Girones, N., Garcia-Bodelon, M.A., Periago, M.V., Chico-Calero, I., Khoubbane, M., Fresno, M. and Mas-Coma, S. (2008) Anaemia in advanced chronic fasciolosis. Acta. Trop., 108(1): 35e43.

35. Mas-Coma, S., Bargues, M.D., Valero, M.A. (2014) Diagnosis of human fascioliasis by stool and blood techniques: Update for the present global scenario. Parasitology, 31(1): e29.

36. Cengiz, Z.T., Yilmaz, H., Dulger, A.C., Cicek, M. (2010) Human infection with Dicrocoelium dendriticum in Turkey. Ann. Saudi. Med., 30(2): 159-161.

37. Mas-Coma, S., Valero, M.A. and Bargues, M.D. (2008) Effects of climate change on animal and zoonotic helminthiases. Rev. Sci. Tech., 27(2): 443-452.

38. Khoramian, H., Arbabi, M., Mahami, O.M., Delavari, M., Hooshyar, H. and Asgari, M.R. (2014) Prevalence of ruminants fascioliasis and their economic effects in Kashan, center of Iran. Asian Pac. J. Trop. Biomed., 4(2): 918-922.

39. Khosravi, A. and Babaahmady, E. (2012) Epidemiology of Fasciola hepatica in Iran. Int. J. Biol., 4(4): 86-90.

40. Abdi, J., Naserifar, R., Rostami, N.M. and Mansouri, V. (2013) New features of fascioliasis in human and animal infections in Ilam Province, Western Iran. Gastroenterol. Hepatol., 6(3): 152-155.

41. Pfukenyi, D.M. and Mukaratirwa, S. (2004) A retrospective study of the prevalence and seasonal variation of F. gigantica in cattle slaughtered in the major abattoirs of Zimbabwe 1990-99. Onderstepoort J. Vet. Res., 71(3): 181-187.

42. Mungube, E.O., Bauni, S.M., Tenhagen, B.A., Wamae, L.W., Nginyi, J.M. and Mugambi, J.M. (2006) The prevalence and economic significance of Fasciola gigantica and Stilesia hepatica in slaughtered animals in the semi-arid coastal Kenya. Trop. Anim. Health Prod., 38(8): 475-483.

43. Phiri, A.M. (2006) Common conditions leading to cattle carcasses and offal condemnations at 3 abattoirs in Western Province of Zambia and their zoonotic implications to consumers. J. S. Afr. Vet. Assoc., 77(1): 28-32.

44. Phiri, A.M. Phiri, I.K., Sikasunge, C.S. and Monrad, J. (2005) Prevalence of fasciolosis in Zambian cattle observed at selected abattoirs with emphasis on age, sex and origin. J. Vet. Med., 52(9): 414-416.

45. Abebe, F., Meharenet, B. and Mekibib, B. (2011) Major fasciolosis infections of cattle slaughtered at the Jimma municipality abattoir and the occurrence of the intermediate hosts in selected water bodies of the zone. J. Anim. Vet. $A d v ., 10(9)$ : 1592-1597.

46. Amer,S., El Khatam, A., Zidan, S., Feng, Y. and Xiao L. (2016) Identity of Fasciola spp. In sheep in Egypt. Parasit. Vectors, 9(1): 623 . 
47. Halimi, M., Farajzadeh, M., Delavari, M., and Arbabi, M. (2015) Developing a climate-based risk map of fascioliasis outbreaks in Iran. J. Infect. Public Health, 8(5): 481-486.

48. Khallaayoune, K. and El Hari, M. (1991) Seasonal variations of Fasciola hepatica infection in goats in the area of Haouz (Morocco). Ann. Rech. Vet., 22(2): 219-226.

49. Taylor, M.A. (2012) Emerging parasitic diseases of sheep. Vet. Parasitol., 189(1): 2-7.
50. Knubben-Schweizer, G. and Torgerson, R.P. (2015) Bovine fasciolosis: Control strategies based on the location of Galba truncatula habitats on farms. Vet. Parasitol., 208(1-2): 77-83.

51. Shiferaw, M.A, Feyisaand, B. and Ephrem, T. (2011) Prevalence of bovine fasciolosis and its economic significance in and around Assela, Ethiopia. Glob. J. Med. Res., 11(3): 491-499.

$* * * * * * * *$ 